\title{
Usability Evaluation of Access Ramps in Transit Buses: Preliminary Findings
}

\author{
James A. Lenker, Ph.D., OTR/L \\ University at Buffalo \\ Uma Damle, M.S., OTR/L \\ New Jersey Veterans Memorial Home \\ Clive D'Souza, Ph.D., Victor Paquet, Sc.D., Terry Mashtare, Ph.D., \\ Edward Steinfeld, Arch.D. \\ University at Buffalo
}

\begin{abstract}
The research literature on access ramps used in transit vehicles is undermined by inconsistent methodologies used across studies, thus providing an inconclusive evidence base for proposed Federal guidelines that would impose a maximum 1:6 slope for all deployment situations. The current study assessed the usability of ramp slope for mobility aid users. Four access ramp slopes were evaluated, with 27 adults representing three populations: manual wheelchair users, power wheelchair users, and people with vision impairment who use a cane or service animal. The dependent variables included five usability measures. The 1:8 and 1:12 slopes were usable and acceptable for most participants. The data indicate that the 1:4 slope is too steep for safe unassisted boarding and disembarking. Many manual wheelchair users lacked the strength needed for unassisted ascent. Power wheelchair users and people with vision impairment expressed safety concerns about descent of steeper slopes. Conclusive interpretations should be cautiously drawn because the sample size was relatively small and did not include users of scooters or ambulation aids.
\end{abstract}

Key Words: Transit, Americans with Disabilities Act, ADA, access ramp, wheelchair access, visual impairment, mobility impairment, access slope

\section{Introduction}

Many people with mobility impairments are dependent on public transportation for completing instrumental activities of daily living, participating in social activities, or engaging in recreational opportunities (Carlsson 2002; Carp 1988; Iwarsson and Stahl 
1999; Hendershot 2003). Community integration and overall quality of life are thus diminished if they encounter barriers to access and use of public transportation (Ståhl 1987). People with disabilities are 2.5 times more likely to experience transportation difficulties than able-bodied people (National Council on Disability 2005). Recent studies substantiate ongoing problems with boarding and disembarking that are experienced by transit bus riders with mobility impairments (Albertson and Falkmer 2005; National Highway Traffic Safety Administration 1997; Nelson(Nygaard Consulting Associates 2008; Frost, Bertocci, and Smalley 2015; Frost, Bertocci, and Sison 2010). Among wheeled mobility equipment users living in areas served by public transit, $40 \%$ indicate that they have wheelchair or scooter access problems with public transit (LaPlante and Kaye 2010). Frost and Bertocci (2010) evaluated 115 adverse incidents involving wheeled mobility devices on large accessible transit buses over a 6-year period in Louisville, Kentucky, and found that $42.6 \%(n=49)$ were associated with ingress/ egress. Among these, 12 of 49 involved the wheeled mobility device tipping forward or rearward while ascending or descending the access ramp, prompting the authors to conclude that "research is needed to examine the adequacy of existing federal legislation and guidelines for accessible ramps used in public transportation" (Frost and Bertocci 2010, 236). A subsequent study of boarding and alighting (Frost, Bertocci, and Smalley 2015) found that $5 \%$ of wheeled mobility device users experience a ramp-related incident when accessing public transit buses and that these incidents were more than five times more likely when the ramp slope exceeded $9.5^{\circ}(1: 6)$.

The need for the current study is driven by a proposed Federal policy that would mandate a 1:6 slope maximum from the bus floor to street level, replacing the current 1:4 maximum. Some stakeholders have expressed concerns that the proposed policy would be problematic for riders with disabilities, and others have argued that the proposal is too stringent from the industry perspective (U.S. Access Board and Department of Transportation 2007b). The research literature on access ramp usability is undermined by inconsistent methodological elements across studies (Nelson|Nygaard Consulting Associates 2008), thus providing an inconclusive basis for either supporting or refuting the proposed guidelines (Nelson|Nygaard Consulting Associates 2008, U.S. Access Board and Department of Transportation 2007a). The current study partially addresses this knowledge gap by evaluating the usability of four access ramp slopes with three populations of mobility-aid users in a laboratory setting.

\section{Background}

Historically, step entrances in transit buses presented a barrier to boarding and disembarking for wheeled mobility users. Electromechanical lifts initially were used to address this accessibility barrier; however, lifts are considered unsatisfactory because they are prone to breakdown, require bus driver assistance, create long loading and unloading delay, and are not helpful for ambulation aid users. The emergence of lowfloor bus designs in the late 1980s lowered the entry and exit height by 3-4 inches (Blennemann 1991), thus reducing physical demands and tripping risks (Schneider and Brechbuhl 1991; Rutenberg 1995). Many low-floor buses also "kneel" at stops, further 
reducing the initial step height by $3-4$ inches. The overall reduction in ground-to-bus floor height has made it feasible to replace lifts with access ramps (Rutenberg 1995).

Compared to wheelchair lifts, access ramps have a simpler design that is less prone to breakdown and requires less maintenance (Blennemann 1991; Schneider and Brechbuhl 1991; Rutenberg 1995). Ramps enable wheeled mobility users to board vehicles more discreetly and in less time (Blennemann 1991; Rutenberg 1995). For drivers, ramps are simpler to deploy and do not require them to leave their seat (Rutenberg 1995; Schneider and Brechbuhl 1991). Ramps can also be used by ambulation aid users, parents pushing strollers, and riders with rolling suitcases or shopping carts, allowing a greater percentage of passengers to enter and exit the bus with reduced effort and assistance (Schneider and Brechbuhl 1991).

However, access ramps are not without drawbacks. Drivers must alert those waiting outside that ramp deployment is imminent. Ramps require substantial horizontal space when deployed, which creates a design challenge for ramp storage. The latter design issue creates a potential tension for policy-makers, who must attempt to balance the accessibility needs of people with mobility impairments with the pragmatics of ramp design for manufacturers. People with mobility impairment naturally prefer gentler slopes; however, ramps with gentler slopes create a design challenge for manufacturers of ramps and buses, who must attempt to create ramps of increasing length that can be electromechanically folded and stowed in a space that is inherently constrained by the available floor space in the entrance area of the bus.

The accessibility of access ramps is affected by their slope, which is often described by a ratio, $a: b$, indicating a rise of $a$ inches for every $b$ inches in run. Table 1 summarizes common slopes in terms of rise:run, percentage gradient, and angle. The Americans with Disabilities Act Accessibility Guidelines (ADAAG) for Transportation Vehicles stipulate that ramp slope may vary from 1:4 to 1:12, depending on the overall rise (U.S. Access Board and Department of Transportation 1998). The U.S. Access Board has proposed a guideline (Architectural and Transportation Barriers Compliance Board 2010) that would establish a maximum slope of 1:6 for all deployment scenarios.

TABLE 1. \begin{tabular}{|c|c|c|}
\hline Slope (rise: run) & Gradient (\%) & Angle $\left(^{\circ}\right)$ \\
\hline
\end{tabular}

Ramp Slope Equivalents

\begin{tabular}{|c|c|c|}
\hline $1: 2$ & $50.0 \%$ & 26.6 \\
\hline $1: 4$ & $25.0 \%$ & 14.0 \\
\hline $1: 6$ & $16.7 \%$ & 9.5 \\
\hline $1: 8$ & $12.5 \%$ & 7.1 \\
\hline $1: 10$ & $10.0 \%$ & 5.7 \\
\hline $1: 12$ & $8.3 \%$ & 4.8 \\
\hline $1: 14$ & $7.1 \%$ & 4.1 \\
\hline $1: 16$ & $6.3 \%$ & 3.6 \\
\hline $1: 18$ & $5.6 \%$ & 3.2 \\
\hline $1: 20$ & $5.0 \%$ & 2.9 \\
\hline
\end{tabular}


People with disabilities have expressed concerns that a 1:6 slope is too steep, potentially increasing the need for driver assistance (Nelson|Nygaard Consulting Associates 2008). Bus and ramp manufacturers who commented on the drafts of the proposed rule provided varied information on this proposed change. Some stated that the proposed 1:6 maximum slope to the roadway is feasible; others stated that the proposed slope would involve significant structural changes to buses or may not be feasible for certain model buses (Architectural and Transportation Barriers Compliance Board 2010). Public transit agencies that commented on the drafts of the proposed rule expressed concern that longer ramps with more complicated mechanical systems (e.g., bi-fold ramps) will be more costly to maintain. They also expressed operational concerns about deploying longer ramps in urban environments with narrow sidewalks and streets. Ramp manufacturers expressed concerns that a 1:6 slope would necessitate longer ramps that would pose design challenges given existing space constraints in the forward section of transit buses (U.S. Access Board and Department of Transportation 2007b). The American Public Transit Association (APTA) asserted that the research literature does not conclusively justify the 1:6 maximum (U.S. Access Board and Department of Transportation 2007b).

\section{Previous Ramp Research}

The accessibility of ramps for buildings was first evaluated in the late 1970s (Steinfeld, Schroeder, and Bishop 1979), which led to the 1:12 slope standard now required for accessible buildings. For transit vehicles, an early study was contracted by the Urban Mass Transportation Administration (UMTA, now the Federal Transit Administration, FTA) (RRC International 1977), which reported findings based on an unspecified number of mobility aid users who evaluated ramp slopes ranging from 1:9 to 1:2. For wheelchair users, slopes of 1:3 could not be negotiated without assistance; unassisted entry was possible for some with slopes between 1:4 and 1:6; and ramp slopes shallower than 1:6 were substantially easier to traverse independently. Ambulation aid users found it very difficult to maintain standing balance at the 1:3 slope and thus necessitated assistance, slopes of 1:4 and 1:6 could be independently traversed with difficulty and often required assistance to exit the bus, and slopes of 1:6 and shallower could be traversed unassisted and without difficulty. This was a groundbreaking study that, nonetheless, had three key limitations: the participant sample was vaguely described in terms of device used and functional ability, the measurement tools were not described, and the research design and procedure were not described in a manner that would support replicability. Since 1977 , there have also been some significant advances in wheelchair seating and mobility technology, notably the introduction of midwheeldrive power chairs, seating and positioning systems that allow more severely-impaired individuals to travel independently, and wheelchair frames that accommodate larger and heavier people (Steinfeld et al. 2010).

Sweeney et al. (1989) evaluated 13 portable ramps ranging from 1:12 to 1:3 with 45 participants representing a diverse age range, wheeled mobility devices, and functional levels. The authors reported that ramp slopes of 1:12 to 1:7 could be negotiated with "relative ease" by $88 \%$ of the self-propelling manual wheelchair users $(n=18)$, compared 
to $52 \%$ of the same group for the 1:6 slope. All seven power wheelchair users traversed the $1: 12$ to $1: 7$ slopes with relative ease, compared to $66 \%$ of the same group for the $1: 6$ slope. Nuanced interpretation of these findings is difficult because the measurement scales were not described for assessing ease of use, and the data were aggregated for slopes ranging from 1:12 to 1:7.

Blennemann (1991) evaluated ramp gradients from 1:16 to 1:5. The findings were based on "workshops" involving an unreported number of wheelchair users, their caregivers, and older adults. Manual wheelchair users navigated the 1:10 slope without difficulty, reported some difficulty with slopes between 1:10 and 1:6, and were unable to negotiate ramps of 1:5 without assistance. Power wheelchair users negotiated slopes as steep as 1:6 without difficulty; however they reported a fear of overturning at a slope of 1:5. Definitive interpretations of these data are not possible because the user groups were not well articulated, the data collection procedures were not described, and the measurement scales were not described.

Sanford, Story, and Jones (1996) evaluated the usability of 6 slopes ranging from 1:8 to 1:20 for 171 participants who used a range of mobility aids. The authors concluded that ramps steeper than 1:12 and longer than 30 feet are difficult to use by manual wheelchair users. Although these findings provide an excellent starting point, the data reflect an experimental ramp length $\left(30^{\prime}\right)$ that is not directly comparable to the typical length $\left(\sim \sigma^{\prime}\right)$ of access ramps in transit vehicles.

It is difficult to derive conclusive slope guidelines from the above literature because key factors (e.g., ramp length, ramp slope, population studied, and measurement tools) are quite disparate and often vaguely described. Because the proposed guidelines have substantial implications for bus manufacturers, access ramp manufacturers, transit operators, and people with disabilities, a more rigorous and systematic study is needed to assure that any new ramp slope guidelines are data-driven. In response to this need, the current study was launched as the initial stage of a two-phase study to assess four access ramp slopes with multiple populations of mobility aid users. The four ramp slopes range from the steepest ramp slope (1:4) allowed by previous U.S. public transit accessibility standards to the slope standard for access to buildings (1:12).

\section{Methodology}

\section{Study Design}

A $3 \times 4$ mixed factorial design was used to evaluate four ramp slopes (1:4, 1:6, 1:8, and 1:12) with three participant groups (manual wheelchair users, power wheelchair users, and persons with vision impairment using a cane or service animal). The range of slopes from 4.8 degrees (1:12) to 14 degrees (1:4) is comparable with the range identified by Bertocci et al. (2014) in their in situ measurement of access ramp slopes as deployed in everyday transit bus use. The dependent variables included five domains of usability: time to ascend the ramp, perceived exertion, perceived difficulty, perceived acceptability, and comparative difficulty of ascent versus descent. 


\section{Participants}

The three user groups represented a range of mobility device users, as suggested by previous authors who emphasized the need for researchers to include diverse disability populations (Hunter-Zaworski and Hron 1993; Rutenberg 1995). The inclusion criteria included age (18-85) and the ability to navigate a 1:12 ramp without assistance. A convenience sample was recruited from a registry of consumers who had previously participated in research at the Center for Inclusive Design \& Environmental Access at the University at Buffalo. Participants were also recruited through the local offices of vocational rehabilitation. As the study progressed, participants were encouraged to distribute recruitment flyers to peers and colleagues. In all, 27 participants were enrolled: 8 manual wheelchair users, 8 powered wheelchair users, and 11 people with vision impairment who used a cane or service animal. Human subjects approval was obtained from an Institutional Review Board at the university. Participants received \$50 in consideration for their time.

\section{Instruments}

\section{Ascent Time}

The time required for ramp ascent was measured using a stopwatch. Consistent time measurements were fostered by taping a starting line at the base of the ramp and a finish line on the platform. Timing was initiated when the forward-most point of the wheelchair crossed the starting line and stopped when the rear-most wheel crossed the finish line.

\section{Borg Rating of Perceived Exertion (RPE) Scale}

Level of perceived exertion was measured using the Borg RPE scale, a 15-point psychophysical scale that captures subjective feelings of physical exertion with scores ranging from 6 (no exertion at all) to 20 (maximal exertion). The validity and reliability of the RPE are well-established (Borg 1998; Chen, Xitao, and Moe 2002; Lagally, Robertson, and Gallagher 2002; Ozcan and Kin-Islar 2007).

\section{Difficulty Rating Scale and Acceptability Rating Scale}

The Difficulty Rating Scale (DRS) and Acceptability Rating Scale (ARS) were developed as measures of environmental usability (Steinfeld and Danford 2000; Danford and Steinfeld 1999). The DRS (Figure 1) measures perceived ease or difficulty of task performance using a 7-point ordinal scale ranging from -3 (very difficult) to +3 (very easy). Respondents rate perceived task difficulty in two steps: (a) indicate if a completed task was "difficult," "moderate." or "easy"; and (b) choose a final rating from three possible options based on the general rating provide in the first step. For example, a respondent who initially indicates that a task was "difficult" would then choose a final rating of barely difficult $(-1)$, moderately difficult $(-2)$, or very difficult $(-3)$. 
FIGURE 1.

Difficulty Rating Scale (DRS)

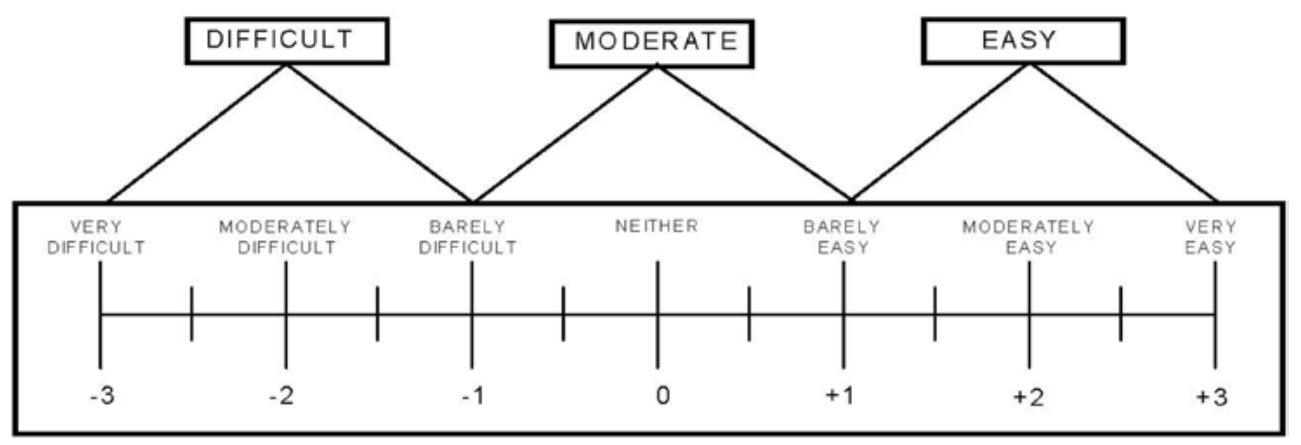

The ARS (Figure 2) measures acceptability of a task using a similarly worded 7-point ordinal scale and two-step rating process. Although the psychometric properties of each have not been rigorously evaluated, there is preliminary evidence of their convergent validity with other functional measures (Steinfeld and Danford 2000).

FIGURE 2.

Acceptability Rating Scale

(ARS)

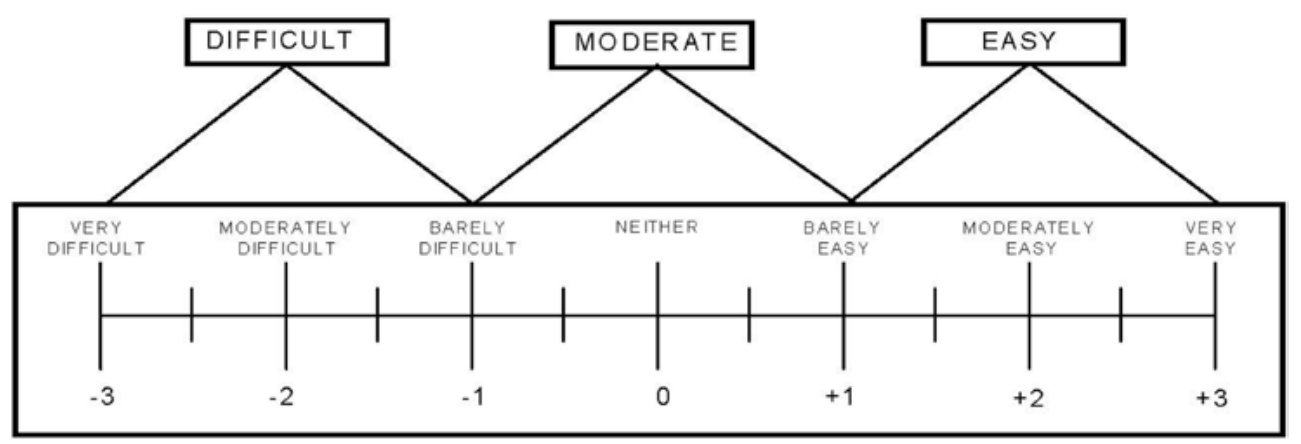

\section{Comparison of Ascent and Descent}

A study-specific rating scale was created (Figure 3) because it was hypothesized that ramp ascent and ramp descent would not be rated at equal difficulty levels by all participant groups. The 5-point ordinal response options ranged from -2 (descent much more difficult) to +2 (ascent much more difficult).

FIGURE 3.

Comparison of ascent and descent scale

\begin{tabular}{|c|c|c|c|c|}
\hline $\begin{array}{c}\text { Descent } \\
\text { much more } \\
\text { difficult }\end{array}$ & $\begin{array}{l}\text { Descent } \\
\text { somewhat more } \\
\text { difficult }\end{array}$ & $\begin{array}{c}\text { About } \\
\text { the same }\end{array}$ & $\begin{array}{c}\text { Ascent } \\
\text { somewhat more } \\
\text { difficult }\end{array}$ & $\begin{array}{c}\text { Ascent } \\
\text { much more } \\
\text { difficult }\end{array}$ \\
\hline-2 & -1 & 0 & 1 & 2 \\
\hline
\end{tabular}

\section{Apparatus}

The experimental apparatus consisted of a wooden ramp ( $6^{\prime}$ long, 40" wide) attached by hinge to a height adjustable, $8^{\prime} \times 8^{\prime}$ platform. The ramp length is consistent with current 1:6 access ramp designs. The width and large landing area were chosen to isolate the effects of slope on ramp usability and minimize the potentially confounding effects of a narrower ramp width and confined landing area for those using larger wheeled 
mobility devices. Four hydraulic jacks, each rated to support $1500 \mathrm{lbs}$, supported the platform. The ramp slope was adjusted by changing the height of the platform from the floor. Four adjustable jack stands were placed underneath the platform as a precaution against jack failure, and a 4-inch yellow curb was mounted along the edges of the platform and the ramp.

\section{Procedure}

Four research assistants performed the data collection protocol. One was primarily responsible for interacting with participants, and the other three served as spotters and changed the ramp slope between trials. The order in which the ramp slopes were presented was counterbalanced within and between groups to minimize order effects. Rest periods were provided as needed throughout the protocol to minimize the effects of fatigue.

Participants were instructed to move as quickly and safely as possible to mimic everyday ramp use. For each slope, participants were given one practice trial and one measurement trial. Thus, each participant experienced a total of eight ascent and descent tasks. One participant requested to propel backwards up the ramp. All other participants propelled themselves in a forward-facing direction for all trials.

The RPE was administered after the ascent task for each slope. The remaining selfreport measures (e.g., DRS ARS, and comparison of ascent and descent difficulty) were administered immediately upon completion of each measurement trial. Participants also were queried for open-ended comments upon completion of each trial.

\section{Statistical Analysis}

Categorical variables were summarized using frequencies and cumulative frequencies. Continuous variables were summarized using means, standard deviations, and medians. A $3 \times 4$ mixed factorial ANOVA model with subject as a blocking variable was used to evaluate the effect of disability group, ramp slope, and disability group by ramp slope interaction on ascent time, RPE, DRS, and ARS. In cases in which the interaction between group and slope was significant, post-hoc tests with a Bonferroni adjustment were conducted to evaluate the pairwise differences. Ordinal regression was used with subject as a blocking variable to study the effect of disability group, ramp slope, and disability group by ramp slope interaction on participants' comparison of ascent and descent difficulty. Spearman correlation was used to evaluate the association among the six dependent variables, ascent time, RPE, DRS, ARS, and comparison of ascent versus descent. A 0.05 nominal significance level was used in all analyses, which were conducted using SAS v.9.2.

\section{Results}

Table 2 summarizes demographics of the 27 participants. The mean age was 47.9 $(\mathrm{SD}=14.4$, range: $22-75)$ years, and the majority $(58.1 \%)$ was male. More than $80 \%(n=22)$ used public transportation at least several times per year, and more than half $(n=14)$ use public transit at least several times per month. All 27 participants attempted each of the four ramp slopes for a total of 108 possible trials. Among these, 14 trials could not be 
completed because of difficulty-nine at the 1:4 slope, four at the 1:6 slope, and one for the 1:8 slope. Manual wheelchair users accounted for 10 of the unsuccessful attempts, and power wheelchairs users accounted for the remaining four.

TABLE 2.

Demographic Characteristics

$(n=27)$

\begin{tabular}{|l|c|c|c|}
\hline \multicolumn{1}{|c|}{ Disability Group } & Gender & $\begin{array}{c}\text { Mean Age (SD) } \\
\text { (yrs) }\end{array}$ & $\begin{array}{c}\text { Age range } \\
\text { (yrs) }\end{array}$ \\
\hline \multirow{2}{*}{ Manual wheelchair users (N=8) } & Male (4) & $48.25(6.4)$ & $41-55$ \\
\cline { 2 - 4 } & Female (4) & $32.75(9.07)$ & $24-42$ \\
\hline \multirow{2}{*}{ Power wheelchair users (N=8) } & Male (7) & $54(13.57)$ & $29-74$ \\
\cline { 2 - 4 } & Female (1) & 44 & 44 \\
\hline \multirow{2}{*}{ Visually impaired (N=11) } & Male (6) & $46.67(14.8)$ & $29-75$ \\
\cline { 2 - 4 } & Female (5) & $49(19.85)$ & $22-63$ \\
\hline
\end{tabular}

Table 3 summarizes the results of the five $3 \times 4$ factorial ANOVAs that were conducted to evaluate the effects of three mobility aids and four ramp slopes on the respective usability indicators. Each is described below.

TABLE 3.

Main Effects and Interaction

\begin{tabular}{|l|l|c|c|c|c|}
\hline \multirow{2}{*}{ Dependent Variable } & \multicolumn{1}{|c|}{ Effect } & df & df & F value & $\begin{array}{c}\text { Significance } \\
\text { (p value) }\end{array}$ \\
\hline \multirow{4}{*}{ Ascent time } & Disability group & 2 & 24 & 8.19 & $0.0019^{*}$ \\
\cline { 2 - 6 } & Slope & 3 & 58 & 12.33 & $<0.0001^{*}$ \\
\cline { 2 - 6 } & Disability group*slope & 6 & 58 & 4.79 & $<0.0005^{*}$ \\
\hline \multirow{4}{*}{ RPE } & Disability group & 2 & 24 & 14.29 & $<0.0001^{*}$ \\
\cline { 2 - 6 } & Slope & 3 & 58 & 42.38 & $<0.0001^{*}$ \\
\cline { 2 - 6 } & Disability group*slope & 6 & 58 & 7.40 & $<0.0001^{*}$ \\
\hline \multirow{4}{*}{ DRS } & Disability group & 2 & 24 & 6.30 & $0.0063^{*}$ \\
\cline { 2 - 6 } & Slope & 3 & 58 & 32.59 & $<0.0001^{*}$ \\
\cline { 2 - 6 } & Disability group*slope & 6 & 58 & 3.75 & $0.0032^{*}$ \\
\hline \multirow{4}{*}{ Ascent vs descent } & Disability group & 2 & 24 & 2.43 & 0.1097 \\
\cline { 2 - 7 } & Slope & 3 & 58 & 23.49 & $<0.0001^{*}$ \\
\cline { 2 - 7 } & Disability group*slope & 6 & 58 & 1.2 & 0.3217 \\
\hline & Disability group & 2 & 24 & $6.59 \#$ & $0.037^{*}$ \\
\cline { 2 - 6 } & Slope & 3 & 58 & $0.45 \#$ & 0.9305 \\
\cline { 2 - 6 } & Disability group*slope & 6 & 58 & $6.15 \#$ & 0.4066 \\
\hline \multirow{2}{*}{$p<05$} & & & &
\end{tabular}

${ }^{*} p<.05$

\# Chi square scores

\section{Ascent Time}

The means and standard deviations for ascent time are presented in Table 4, and Figure 4 depicts the mean values for each group-slope combination. The assumptions for ANOVA were met using a natural log transformation to stabilize the variance.

The ANOVA results indicated significant main effects for group $(p=0.0019)$ and slope 
$(p<0.0001)$ and a significant interaction between group and slope $(p=0.0005)$. The post-hoc analysis indicated that the interaction was driven by the longer ascent time experienced by manual wheelchair users at the steepest slopes (1:4 and 1:6) compared to the shallowest slopes (1:8 and 1:12) - in contrast with the relatively consistent ascent times experienced by the other two groups across all four slopes.

TABLE 4.

Mean Ascent Time (in seconds) for Each User Group and Slope Combination

\begin{tabular}{|l|c|c|c|}
\hline \multicolumn{1}{|c|}{ Ramp Slope } & $\begin{array}{c}\text { Manual WC } \\
\text { Mean (SD) }\end{array}$ & $\begin{array}{c}\text { Power WC } \\
\text { Mean (SD) }\end{array}$ & $\begin{array}{c}\text { Visually-Impaired } \\
\text { Mean (SD) }\end{array}$ \\
\hline $1: 4(n=18)^{*}$ & $16.25(.35)$ & $8.20(3.35)$ & $9.32(3.17)$ \\
\hline $1: 6(n=23)$ & $15.80(7.26)$ & $7.86(2.97)$ & $8.64(2.75)$ \\
\hline $1: 8(n=26)$ & $13.43(6.90)$ & $8.00(3.12)$ & $8.14(2.18)$ \\
\hline $1: 12(n=27)$ & $13.13(10.62)$ & $8.31(4.04)$ & $7.95(2.13)$ \\
\hline
\end{tabular}

* Indicates number of participants who completed each slope

FIGURE 4.

Mean ascent time for each user group across slopes

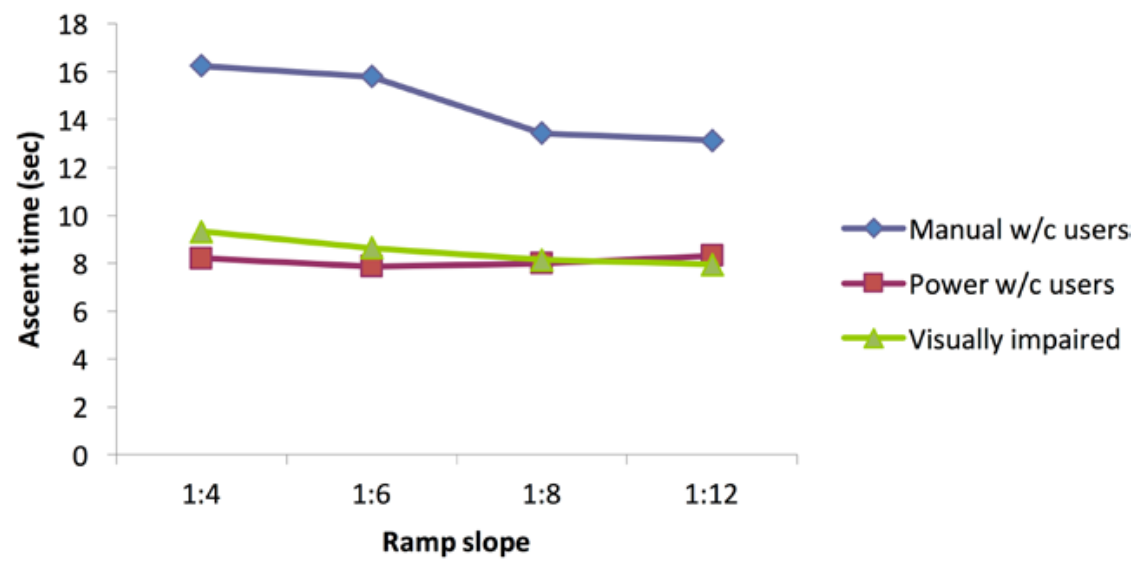

\section{Rating of Perceived Exertion}

The means and standard deviations for the RPE are presented in Table 5. Figure 5 depicts the mean values for each group-slope combination. The assumptions for ANOVA were met using a weighted least squares procedure to stabilize the variance. The ANOVA results indicated significant main effects for group $(p<0.0001)$ and slope $(p<0.0001)$ and a significant interaction between group and slope $(p=0.0001)$. The post-hoc analysis indicated that the interaction was driven by the difference in RPE ratings reported by manual wheelchair users, compared to the other two groups, for the steeper slopes (1:4 and 1:6), which narrowed for the 1:8 slope and diminished substantially for the 1:12 slope.

TABLE 5.

Mean RPE Scores for Each User Group and Slope Combination

\begin{tabular}{|l|c|c|c|}
\hline Ramp Slope & $\begin{array}{c}\text { Manual WC Users } \\
\text { Mean (SD) }\end{array}$ & $\begin{array}{c}\text { Power WC Users } \\
\text { Mean (SD) }\end{array}$ & $\begin{array}{c}\text { Visually-Impaired } \\
\text { Mean (SD) }\end{array}$ \\
\hline $1: 4(n=18)^{*}$ & $15.5(2.12)$ & $7.8(2.95)$ & $10.82(3.68)$ \\
\hline $1: 6(n=23)$ & $13.6(3.29)$ & $7.68(2.91)$ & $10.09(4.04)$ \\
\hline $1: 8(n=26)$ & $9.86(3.08)$ & $6.38(1.06)$ & $7.18(3.28)$ \\
\hline $1: 12(n=27)$ & $7.75(1.75)$ & $6.13(0.35)$ & $6.73(2.1)$ \\
\hline
\end{tabular}

* Indicates number of participants who completed each slope 
FIGURE 5.

Mean RPE scores for each user group across slopes

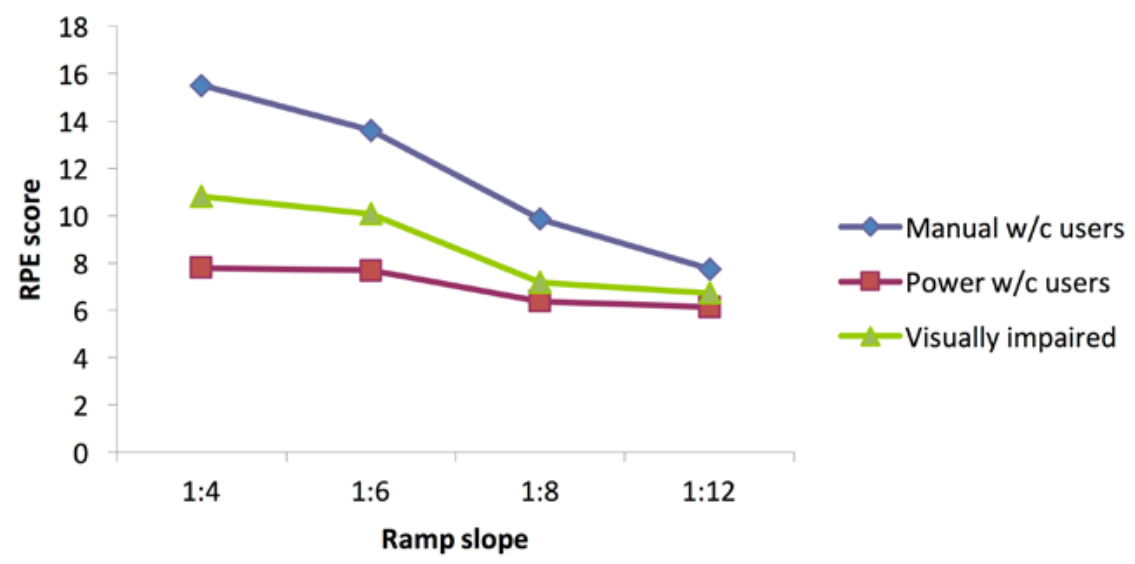

Higher scores indicate greater perceived exertion

\section{Difficulty Rating Scale}

The means and standard deviations for the DRS are presented in Table 6. Figure 6 depicts the mean values for each group-slope combination. The studentized residuals plots were satisfactory to meet ANOVA assumptions. The ANOVA results indicated significant main effects for group $(p=0.0063)$ and slope $(p<0.0001)$ and a significant interaction between group and slope $(p=0.0032)$. The post-hoc analysis indicated that the interaction was driven by the difference in DRS ratings reported by manual wheelchair users, compared to the other two groups, for the steeper slopes (1:4 and 1:6), which diminish substantially for the 1:12 slope.

TABLE 6.

Mean DRS Scores for Each

User Group and Slope

Combination

\begin{tabular}{|l|c|c|c|}
\hline Ramp slope & $\begin{array}{c}\text { Manual WC Users } \\
\text { Mean (SD) }\end{array}$ & $\begin{array}{c}\text { Power WC Users } \\
\text { Mean (SD) }\end{array}$ & $\begin{array}{c}\text { Visually-Impaired } \\
\text { Mean (SD) }\end{array}$ \\
\hline $1: 4(n=18)^{*}$ & $-2.75(0.35)$ & $-0.3(1.79)$ & $0.82(1.99)$ \\
\hline $1: 6(n=23)$ & $-0.9(1.52)$ & $1.79(1.63)$ & $1.41(1.77)$ \\
\hline $1: 8(n=26)$ & $1.57(1.51)$ & $2.94(0.18)$ & $2.36(1.8)$ \\
\hline $1: 12(n=27)$ & $2.75(0.46)$ & $3.0(0)$ & $2.64(1.21)$ \\
\hline
\end{tabular}

* Indicates number of participants who completed each slope

FIGURE 6.

Mean DRS scores for each user group across slopes

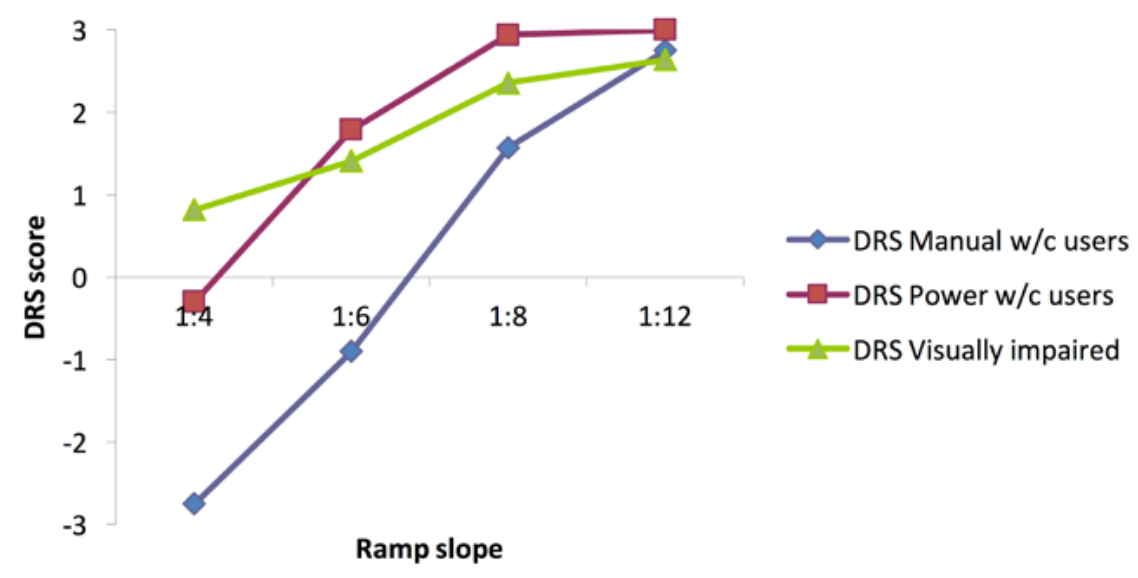

Positive DRS ratings indicate relative ease of task; negative ratings reflect relative task difficulty. 


\section{Acceptability Rating Scale}

The means and standard deviations for the ARS are presented in Table 7. Figure 7 depicts the mean values for each group-slope combination. The studentized residuals plots were satisfactory for meeting ANOVA assumptions. The ANOVA results indicated a non-significant main effect for group $(p=0.1097)$ and a non-significant interaction between group and slope $(p=0.3217)$. A significant main effect for slope $(p<0.0001)$ was seen, indicating that there were significant differences in level of acceptability across slopes. Given that there was not a significant interaction between group and slope, no post hoc analysis was conducted for the ARS data.

TABLE 7.

Mean ARS Scores for Each User Group and Slope Combination

\begin{tabular}{|l|c|c|c|}
\hline Ramp slope & $\begin{array}{c}\text { Manual WC Users } \\
\text { Mean (SD) }\end{array}$ & $\begin{array}{c}\text { Power WC Users } \\
\text { Mean (SD) }\end{array}$ & $\begin{array}{c}\text { Visually-Impaired } \\
\text { Mean (SD) }\end{array}$ \\
\hline $1: 4(n=18)^{*}$ & $-1.25(2.47)$ & $-0.2(1.79)$ & $-0.18(2.56)$ \\
\hline $1: 6(n=23)$ & $0.50(1.66)$ & $2.64(0.48)$ & $1.82(1.47)$ \\
\hline $1: 8(n=26)$ & $1.93(1.79)$ & $3.0(0)$ & $2.45(1.51)$ \\
\hline $1: 12(n=27)$ & $3.0(0)$ & $2.88(0.35)$ & $3.0(0)$ \\
\hline
\end{tabular}

* Indicates number of participants who completed each slope

FIGURE 7.

Mean ARS scores for each user group across slopes

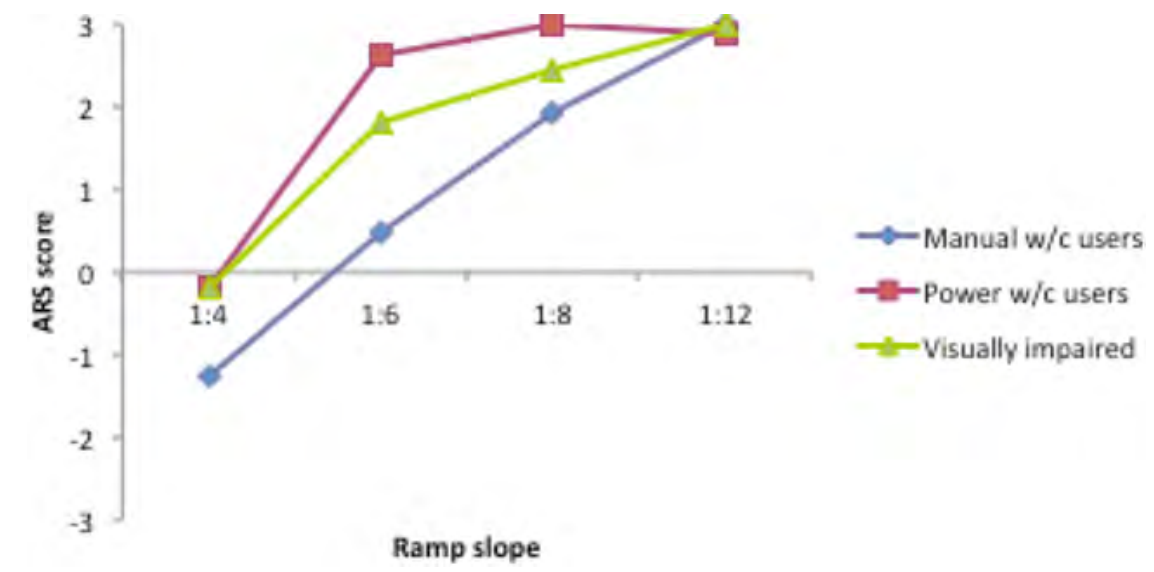

Positive ARS ratings indicate relative acceptability of task; negative ratings reflect relative unacceptability of task.

\section{Comparison of Ascent and Descent}

The means and standard deviations for ascent-versus-descent ratings are presented in Table 8. Figure 8 depicts the mean values of ascent vs. descent for each groupslope combination. Ordinal regression was used to analyze the results with subjects as a blocking variable. The results indicated a significant main effect for group (Chisquare $=6.59, \mathrm{df}=2, \mathrm{p}=0.037$ ), a non-significant main effect for slope (Chi-square $=0.45$, $\mathrm{df}=3, \mathrm{p}=0.9305)$, and a non-significant interaction between group and slope (Chisquare $=6.15, \mathrm{df}=6, \mathrm{p}=0.4066$ ). . Manual wheelchair users rated ascent to be more difficult than descent across all ramp slopes, whereas power wheelchair users and people with vision impairment rated descent to be slightly more difficult-to-neutral across all four slopes. 
TABLE 8.

Mean Scores on Scale Comparing Difficulty of Ascent and Descent

\begin{tabular}{|l|c|c|c|}
\hline Ramp slope & $\begin{array}{c}\text { Manual WC } \\
\text { Mean (SD) }\end{array}$ & $\begin{array}{c}\text { Power WC } \\
\text { Mean (SD) }\end{array}$ & $\begin{array}{c}\text { Visually-Impaired } \\
\text { Mean (SD) }\end{array}$ \\
\hline $1: 4(n=18)^{*}$ & $1.5(0.7)$ & $-0.6(1.1)$ & $-0.27(1.2)$ \\
\hline $1: 6(n=23)$ & $1(0.7)$ & $-0.29(1.0)$ & $-0.18(1.1)$ \\
\hline $1: 8(n=26)$ & $0.86(0.7)$ & $0(0.5)$ & $-0.18(0.8)$ \\
\hline $1: 12(n=27)$ & $0.5(0.5)$ & $0(0.5)$ & $0(0.5)$ \\
\hline
\end{tabular}

* Indicates number of participants who completed each slope Positive values indicate that ascent was rated to be more difficult than descent; negative values indicate that descent was rated to be more difficult than ascent.

FIGURE 8.

Mean scores on scale comparing ascent and descent for each user group across slopes

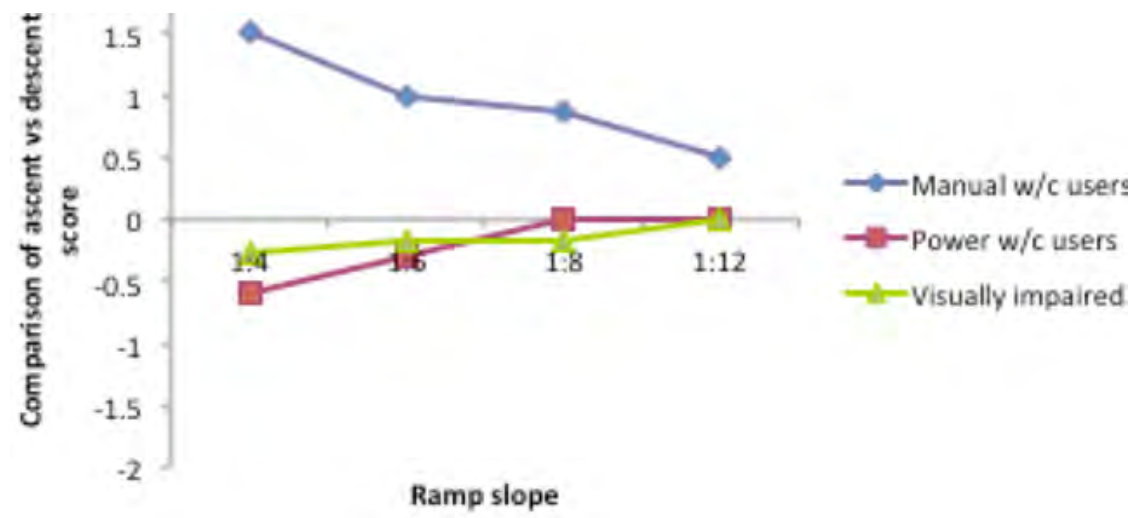

Positive ratings indicate that ascent is more difficult; negative ratings indicate that descent is more difficult.

\section{Associations among Key Dependent Measures}

Table 9 shows correlations among ascent time, RPE, DRS, and ARS scales. There was a statistically-significant, negative correlation between RPE and DRS for all four slopes. The correlation was strong for all slopes except 1:12, which exhibited moderate correlation. There was a statistically-significant, negative correlation between RPE and ARS for all slopes except 1:12. The correlation between RPE and ARS was moderate for 1:4 $(r=-0.525)$ and 1:8 $(r=-0.673)$ and strong for 1:6 $(r=-0.831, p<.0001)$. There was a statistically-significant, positive correlation between ARS and DRS for all the slopes except 1:12. The correlation between ARS and DRS was moderate for slope $=1: 4$ $(r=0.664)$ and strong for 1:6 $(r=0.834)$ and 1:8 $(r=0.879)$. For all slopes except 1:8, ascent time did not correlate with RPE, DRS, or ARS at a statistically-significant level. 
TABLE 9.

Correlations among Key Dependent Variables

\begin{tabular}{|c|c|c|c|}
\hline $\begin{array}{l}\text { Dependent } \\
\text { Variables }\end{array}$ & Slopes & $\mathbf{r}$ & $\begin{array}{l}\text { Significance } \\
\text { ( } p \text { value) }\end{array}$ \\
\hline \multirow{4}{*}{ RPE and DRS } & $1: 4(n=18)^{*}$ & -0.711 & $0.000^{* *}$ \\
\hline & $1: 6(n=23)$ & -0.813 & $<0.000^{* *}$ \\
\hline & $1: 8(n=26)$ & -0.78 & $<0.000^{* *}$ \\
\hline & $1: 12(n=27)$ & -0.557 & $0.003^{* *}$ \\
\hline \multirow{4}{*}{ RPE and ARS } & $1: 4(n=18)$ & -0.525 & $0.025^{* *}$ \\
\hline & $1: 6(n=23)$ & -0.831 & $<0.000^{* *}$ \\
\hline & $1: 8(n=26)$ & -0.673 & $0.000^{* *}$ \\
\hline & $1: 12(n=27)$ & 0.136 & 0.499 \\
\hline \multirow{4}{*}{ DRS and ARS } & $1: 4(n=18)$ & 0.664 & $0.003^{* *}$ \\
\hline & $1: 6(n=23)$ & 0.834 & $<0.000^{* *}$ \\
\hline & $1: 8(n=26)$ & 0.879 & $<0.000^{* *}$ \\
\hline & $1: 12(n=27)$ & 0.069 & 0.732 \\
\hline \multirow{4}{*}{$\begin{array}{l}\text { Ascent time } \\
\text { and RPE }\end{array}$} & $1: 4(n=18)$ & 0.276 & 0.268 \\
\hline & $1: 6(n=23)$ & 0.252 & 0.245 \\
\hline & $1: 8(n=26)$ & 0.414 & $0.035^{* *}$ \\
\hline & $1: 12(n=27)$ & 0.333 & 0.09 \\
\hline \multirow{4}{*}{$\begin{array}{l}\text { Ascent time } \\
\text { and DRS }\end{array}$} & $1: 4(n=18)$ & -0.342 & 0.165 \\
\hline & $1: 6(n=23)$ & -0.138 & 0.53 \\
\hline & $1: 8(n=26)$ & -0.403 & $0.041^{* *}$ \\
\hline & $1: 12(n=27)$ & -0.03 & 0.883 \\
\hline \multirow{4}{*}{$\begin{array}{l}\text { Ascent time } \\
\text { and ARS }\end{array}$} & $1: 4(n=18)$ & -0.463 & 0.525 \\
\hline & $1: 6(n=23)$ & -0.159 & 0.469 \\
\hline & $1: 8(n=26)$ & -0.544 & $0.004^{* *}$ \\
\hline & $1: 12(n=27)$ & 0.063 & 0.754 \\
\hline
\end{tabular}

* Indicates number of participants who completed each slope ${ }^{* *} p<0.05,<0.01,<0.001$

\section{Discussion}

Data from multiple measures of usability indicate that the 1:4 access ramp slope is too steep for unassisted boarding and disembarking. Clearly, this slope is a potential barrier for manual wheelchair users who lack the strength to propel independently over the relatively short distance required by an access ramp. The ascent times for manual wheelchair users completing the 1:4 and 1:6 slopes were substantially greater than the comparison groups. This not only reflects the physical difficulty of the steeper slopes but also portends extended dwell times and needs for assistance that could also be problematic for bus operators striving to maintain timely fixed-route service and minimize occupational injuries for bus operators.

The 1:4 slope was intimidating for some power wheelchair users who declined to complete the ascent task because of concerns about their safety. Several expressed apprehension that their footrests might collide with the ramp and that their chair 
might tip over. For 1:4 and 1:6 slopes, we observed several power wheelchair users who deviated from straight-line propulsion and exhibited lurching wheelchair movements at the top-of-ramp grade transition, which introduced perturbations in upright trunk posture and reflected the challenge of maintaining a straight path and steady speed.

In contrast, people with visual impairment could ascend all ramp slope conditions independently. Similar to power wheelchair users, their ascent times and ratings of exertion were substantially similar across all slope conditions, though they rated descent to be slightly more difficult than ascent for the three steepest slopes. Most were emphatic that the 1:4 slope was too steep, and several exhibited momentarily unsteady standing balance at the top-of-ramp grade transition under the 1:4 and 1:6 slope conditions. Participants from all three groups conveyed unprompted comments expressing concern that their performance would be diminished under adverse weather conditions, e.g., rain, ice, or snow.

The 1:8 slope appears to be generally usable and acceptable for all three user groups. However, manual wheelchair users exhibited mean ascent times at 1:8 and 1:12 that were more than 5 seconds slower than the two comparison groups, which is not inconsequential to bus operators seeking to minimize dwell times. The 1:12 slope elicited the least differentiation among the three groups, who all completed the ascent independently, reported similar ratings of exertion and acceptability, did not exhibit any balance or tracking problems, and did not report any safety concerns. The performance of manual wheelchair users appear generally consistent with findings of Sweeney and colleagues (1989) and Blennemann (1991), although differences in research methods and slope conditions, make direct comparison impossible.

\section{Methodological Insights}

The results indicate that ramp usability is best evaluated through the lens of diverse disability populations and complementary usability measures. Excluding key populations or focusing on a single indicator of usability would risk loss of important insights regarding ramp usage. Whereas the usability for manual wheelchair users was most tellingly revealed by ascent times, the safety concerns of power wheelchair users and those with vision impairment were captured by their ratings of acceptability and comparison of ascent and descent. The comparability of ascent and descent difficulty for powered wheelchair users at all slopes contrasts the findings of Frost et al. (2015), whose safety data found that ascent was more challenging that descent. This difference might be caused by the confined interior space at the upper ramp landing and the narrower ramp width that are found in operational buses.

Data from the DRS and ARS demonstrate their promise. The DRS correlated well with the RPE, particularly for conditions involving moderate-to-high levels of effort. The DRS was less discerning for conditions involving low perceived effort. The ARS data were less strongly correlated with the DRS and RPE under conditions involving moderate-tohigh effort, and did not distinguish participant groups under conditions of low effort. Although the DRS and ARS require further psychometric evaluation, the data suggest 
that both are potentially valuable in studies for which the constructs of difficulty and acceptability of environments are relevant.

The study-specific measure comparing difficulty of ascent and descent uncovered key differences that were not otherwise revealed by the other measures. Manual wheelchair users felt ascent was much more difficult than descent because of the physical effort, whereas power wheelchair and vision impairment groups reported that descent was more difficult for them at 1:4 and 1:6 and neither more or less difficult at 1:8 and 1:12.

\section{Limitations}

The research methodology had several limitations. The relatively small sample did not include users of scooters and ambulation aids, which comprise the two largest populations of mobility aid users. Although further research is yet needed with these populations, several useful findings can be seen at this juncture from the data with wheelchair users and persons with vision impairment, especially regarding the usability challenges presented by 1:4 and 1:6 ramp slopes. In addition, the data were collected in a lab setting that featured two idealized performance conditions: (a) the indoor setting does not reflect the performance degradation that occurs with outdoor climatic conditions (e.g., temperature, rain, ice, snow, wind) that influence usability of ramps in northern climates (Ripat, Brown, and Ethans 2015); and (b) the ramp apparatus was 40 inches wide, a wider-than-typical dimension that was chosen in order to eliminate the potentially confounding effects of narrower ramp widths on the ability to navigate different grades. The data from these conditions thus suggest a baseline of best-case performance that can be a useful basis for comparison with future data captured in real-world environments. We also used several measurement tools (e.g., DRS, ARS, and comparison of ascent and descent) that had limited use in previous studies. These measures were nonetheless chosen for their relevance to our research objectives and low response burden. The correlations found among DRS, ARS, ascent times, and RPE data suggest that the measures behaved largely as hoped and merit continued deployment in future usability studies.

\section{Conclusions}

The data indicate that the 1:4 slope is too steep for safe unassisted boarding and disembarking. Many manual wheelchair users lacked the strength needed for unassisted ascent. Power wheelchair users and people with vision impairment expressed safety concerns about descent of steeper slopes. Additional interpretations should be cautiously drawn because the sample size was relatively small and did not include users of scooters or ambulation aids. It should be emphasized that deployed ramp slope is not purely a design issue for bus manufacturers. A variety of environmental design factors may also contribute to the ramp slopes achievable everyday situations, e.g., availability of raised platforms, accessibility of bus stops and sidewalks leading to bus stop areas, illegally parked cars that block sidewalk deployment of ramps at bus stop areas, and accumulations of snow at bus stop areas during winter months.

Future research on access ramp usability is needed in three areas: (a) evaluation of additional populations of mobility aid users, including those who use ambulation aids 
and scooters; (b) evaluation of the usability of ramps with 1:6 and 1:8 slopes using a configuration of width and landing area that more closely approximates the dimensions found on operational buses; and (c) evaluation under environmental conditions that reflect outdoor winter weather.

\section{References}

Albertson, P. , and T. Falkmer. 2005. "Is There a Pattern in European Bus and Coach Incidents? A Literature Analysis with Special Focus on Injury Causation and Injury Mechanisms." Accident Analysis and Prevention, 37: 225-233.

Architectural and Transportation Barriers Compliance Board. 2010. "Americans with Disabilities Act (ADA) Accessibility Guidelines for Transportation Vehicles: Notice of Proposed Rulemaking." Federal Register: United States Government.

Bertocci, G., K. L. Frost, and C. Smalley. 2014. "Public Transit Bus Ram Slopes Measured in Situ." Disability \& Rehabilitation: Assistive Technology: 1-6.

Blennemann, F. 1991. "The Low Floor Bus Concept: Advantages for the Elderly and Handicapped." Planning and Transport Research and Computation, P349: 29-42.

Borg, G. 1998. Borg's Perceived Exertion and Pain Scales. Champaign, IL: Human Kinetics.

Carlsson, G. 2002. "Catching the Bus in Old Age: Methodological Aspects of Accessibility Assessments in Public Transport." Department of Clinical Neuroscience, Lund University, Sweden.

Carp, F. 1988. "Significance of Mobility for the Well-Being of the Elderly." In Transportation in an Aging Society: Improving Mobility and Safety of Older Persons. Washington, DC: National Academy Press.

Chen, M. J., F. Xitao, and S. T. Moe. 2002. "Criterion-Related Validity of the Borg Ratings of Perceived Exertion Scale in Healthy Individuals: A Meta-Analysis." Journal of Sports Sciences, 20: 873-899.

Danford, G. S., and E. Steinfeld. 1999. "In Search of Methods for Measuring Enabling Environments." In Steinfeld, E., and G. S. Danford (eds.), Measuring Enabling Environments. New York: Kluwer Academic/Plenum.

Frost, K. L., and G. Bertocci. 2010. "Retrospective Review of Adverse Incidents Involving Passengers Seated in Wheeled Mobility Devices While Travelling in Large Accessible Transit Vehicles." Medical Engineering \& Physics, 32: 230-236.

Frost, K. L., G. Bertocci, and S. Sison. 2010. “Ingress/Egress Incidents Involving Wheelchair Users in a Fixed-Route Public Transit Environment." Journal of Public Transportation,13(4): 41-62.

Frost, K. L., G. Bertocci, and C. Smalley. 2015. "Ramp-Related Incidents Involving Wheeled Mobility Device Users During Transit Bus Boarding/Alighting." Archives of Physical Medicine \& Rehabilitation, 96: 928-33. 
Hendershot, G. 2008. Community Participation and Life Satisfaction 2003. Available from http://www.nod.org/index.cfm?fuseaction=Feature.showFeature\&FeatureID=1129, accessed March 12, 2008.

Hunter-Zaworski, K. M., and M. Hron. 1993. "Improving Bus Accessibility Systems for Persons with Sensory and Cognitive Impairments." Final Report, Oregon State University, Corvallis, Federal Transit Administration.

Iwarsson, S., and A. Stahl. 1999. "Traffic Engineering and Occupational Therapy: A Collaborative Approach for Future Directions." Scandinavian Journal of Occupational Therapy, 6: 21-28.

Lagally, K. M., R. J. Robertson, and K. I. Gallagher. 2002. “Perceived Exertion, Electromyography, and Blood Lactate During Acute Bouts of Resistance Exercise." Medicine and Science in Sports and Exercise, 34: 552-559.

LaPlante, M. P., and H. S. Kaye. 2010. "Demographics and Trends in Wheeled Mobility Equipment Use and Accessibility in the Community." Assistive Technology, 22: 3-17.

National Council on Disability. 2005. The Current State of Transportation for People with Disabilities in the United States. Washington, DC: National Council on Disability.

National Highway Traffic Safety Administration. 1997. "Wheelchair-Users' Injuries and Deaths Associated with Motor Vehicle Related Incidents."

Nelson|Nygaard Consulting Associates. 2008. "Status Report on the Use of Wheelchairs and Other Mobility Devices on Public and Private Transportation." Washington, DC: Easter Seals Project ACTION.

Ozcan, A., and A. Kin-Islar. 2007. "The Reliability and Validity of Regulating Exercise Intensity by Ratings of Perceived Exertion in Step Dance Sessions." Journal of Strength and Conditioning Research, 21: 296-300.

Ripat, J. D., C. L. Brown, and K. D. Ethans. 2015. "Barriers to Wheelchair Use in Winter." Arch Phys Med Rehabil, 96(6): 1117-1122. doi: 10.1016/j.apmr.2015.01.020.

RRC International. 1977. "Small Transit Bus Requirements Study: Performance Specifications for Advanced Design: Small Urban Transit Bus." Washington, DC: Urban Mass Transportation Administration.

Rutenberg, U. 1995. “Urban Transit Bus Accessibility Considerations." Rutenberg Design Inc., Canadian Urban Transit Association.

Sanford, J. A., M. F. Story, and M. L. Jones. 1996. "Accessibility Requirements for Ramp Slopes." Paper presented at 1996 RESNA Annual Conference.

Schneider, W., and A. Brechbuhl. 1991. "Defining the Low-Floor Bus: Its Advantages and Disadvantages." Paper presented at 49th UITP Congress, Stockholm.

Ståhl, A. 1987. "Changing Mobility Patterns and the Ageing Population in Sweden." Transportation Research Record, 1135: 37-41.

Steinfeld, E., and G. S. Danford. 2000. "Measuring Handicapping Environments." Journal of Rehabilitation Outcomes Measurement, 4(4): 5-8. 
Steinfeld, E., J. L. Maisel, D. Feathers, and C. R. D'Souza. 2010. "Anthropometry and Standards for Wheeled Mobility: An International Comparison." Assistive Technology, 22: 51-67.

Steinfeld, E., S. Schroeder, and M. Bishop. 1979. "Accessible Buildings for People with Walking and Reaching Limitations." U.S. Department of Housing and Urban Development. Washington, DC.

Sweeney, G. M., A. K. Clarke, R. A. Harrison, and S. J. Bulstrode. 1989. "An Evaluation of Portable Ramps." British Journal of Occupational Therapy, 52: 473-75.

U.S. Access Board and Department of Transportation. 1998. "ADA Accessibility Guidelines for Transportation Vehicles." Federal Register (36 Cfr Part 1192). Available from http://www.access-board.gov/transit/html/vguide.htm.

U.S. Access Board and Department of Transportation. 2007a. "Draft Revisions to the ADA Accessibility Guidelines for Buses and Vans,." Available from http://www. access-board.gov/vguidedraft.htm, accessed July 22, 2008.

U.S. Access Board and Department of Transportation. 2007b. "Public Comments on the Draft Update of Guidelines for Buses and Vans." Available from http://www.accessboard.gov/transit/comments/, accessed July 22, 2008.

\section{About the Authors}

JAMES LENKER (lenker@buffalo.edu) is an Associate Professor in the Department of Rehabilitation Science at the University at Buffalo.

UMA DAMLE is an Occupational Therapist at New Jersey Veterans Memorial Home in Edison.

Clive D'Souza is an Assistant Professor in the Department of Industrial and Operations Engineering at the University of Michigan, Ann Arbor.

Victor PaqUet is an Associate Professor in the Department of Industrial \& Systems Engineering at the University at Buffalo.

Terry L. MAshtare is a Research Assistant Professor in the Department of Biostatistics at the University of Buffalo.

EDWARD Steinfeld is a Professor in the Department of Architecture at the University at Buffalo. 